\title{
Effect of genomic selection on rate of inbreeding and coancestry and effective population size of Holstein and Jersey cattle populations
}

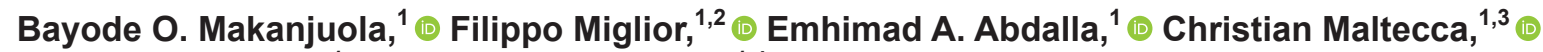 \\ Flavio S. Schenkel, ${ }^{1}$ (i) and Christine F. Baes ${ }^{1,4 *}$ (]) \\ ${ }^{1}$ Centre for Genomic Improvement of Livestock, Department of Animal Biosciences, University of Guelph, Guelph, ON, N1G 2W1 Canada \\ ${ }^{2}$ Ontario Genomics, ON, M5G 1 M1 Canada \\ ${ }^{3}$ Department of Animal Science and Genetics Program, North Carolina State University, Raleigh 27607 \\ ${ }^{4}$ Institute of Genetics, Vetsuisse Faculty, University of Bern, Bern 3001, Switzerland
}

\section{ABSTRACT}

Genetic diversity in livestock populations is a significant contributor to the sustainability of animal production. Also, genetic diversity allows animal production to become more responsive to environmental changes and market demands. The loss of genetic diversity can result in a plateau in production and may also result in loss of fitness or viability in animal production. In this study, we investigated the rate of inbreeding $(\Delta F)$, rate of coancestry $(\Delta f)$, and effective population size $\left(N_{e}\right)$ as important quantitative indicators of genetic diversity and evaluated the effect of the recent implementation of genomic selection on the loss of genetic diversity in North American Holstein and Jersey dairy cattle. To estimate the rate of inbreeding and coancestry, inbreeding and coancestry coefficients were calculated using the traditional pedigree method and genomic methods estimated from segment- and marker-based approaches. Furthermore, we estimated $N_{e}$ from the rate of inbreeding and coancestry and extent of linkage disequilibrium. A total of 205,755 and 89,238 pedigreed and genotyped animals born between 1990 and 2018 inclusively were available for Holsteins and Jerseys, respectively. The estimated average pedigree inbreeding coefficients were 7.74 and $7.20 \%$ for Holsteins and Jerseys, respectively. The corresponding values for the segment and markerby-marker genomic inbreeding coefficients were 13.61, 15.64, and $31.40 \%$ for Holsteins and 21.16, 22.54, and $42.62 \%$ for Jerseys, respectively. The average coancestry coefficients were 8.33 and $15.84 \%$ for Holsteins and 9.23 and $23.46 \%$ for Jerseys with pedigree and genomic measures, respectively. Generation interval for the whole 29-yr time period averaged approximately

\footnotetext{
Received December 4, 2019.

Accepted February 13, 2020.

*Corresponding author: cbaes@uoguelph.ca
}

$5 \mathrm{yr}$ for all selection pathways combined. The $\Delta F$ per generation based on pedigree, segment, and marker-bymarker genomic measures for the entire 29-yr period was estimated to be $0.75,1.10,1.16$, and $1.02 \%$ for Holstein animals and $0.67,0.62,0.63$, and $0.59 \%$ for Jersey animals, respectively. The $\Delta f$ was estimated to be 0.98 and $0.98 \%$ for Holsteins and 0.73 and $0.78 \%$ for Jerseys with pedigree and genomic measures, respectively. These $\Delta F$ and $\Delta f$ translated to an $N_{e}$ that ranged from 43 to 66 animals for Holsteins and 64 to 85 animals for Jerseys. In addition, the $N_{e}$ based on linkage disequilibrium was 58 and 120 for Holsteins and Jerseys, respectively. The 10 -yr period that involved the application of genomic selection resulted in an increased $\Delta F$ per generation with ranges from 1.19 to $2.06 \%$ for pedigree and genomic measures in Holsteins. Given the rate at which inbreeding is increasing after the implementation of genomic selection, there is a need to implement measures and means for controlling the rate of inbreeding per year, which will help to manage and maintain farm animal genetic resources.

Key words: genetic diversity, rate of inbreeding, effective population size, dairy cattle

\section{INTRODUCTION}

The proper management of genetic resources in livestock populations is vital to sustain the output of animal products demanded by the growing population. In addition, the dynamics associated with climate change, as well as market demand fluctuations, require a substantial amount of genetic diversity to forestall any plateau in production. Dairy cattle production has benefitted from the adoption and implementation of sophisticated statistical tools such as (1) selection index (Hazel and Lush, 1942); (2) BLUP (Henderson, 1975); and (3) more recently genomic prediction using BLUP and Bayesian methods (Meuwissen et al., 2001), which allow for the estimation of breeding values to determine 
animals with higher genetic potential for economically important traits. However, the maximization of genetic gain is usually accompanied by a loss of genetic diversity. The loss of genetic diversity in dairy cattle populations is attributable to the high selection intensity on the male side, co-selection of family members with the use of BLUP, and reduction of the generation interval and Mendelian sampling variance due to the use of genomic selection (GS; see Howard et al., 2017 for a review). Consequently, this leads to an increase in the level of inbreeding, a reduction in the effective population size $\left(\boldsymbol{N}_{e}\right)$ and the random loss or fixation of alleles caused by genetic drift and selection. Furthermore, a loss of fitness and reduction in mean value of any trait of interest due to the exposure and accumulation of deleterious recessive homozygotes has been observed across numerous studies and is more evident for lowly heritable traits (VanRaden et al., 2011a; Bjelland et al., 2013; Pryce et al., 2014; Baes et al., 2019; Guarini et al., 2019).

The awareness of the detrimental effects of increased homozygosity due to inbreeding prompted the development of actions that aim to minimize accumulation of inbreeding over time $(\boldsymbol{\Delta} \boldsymbol{F})$. Meuwissen (1997) introduced optimum contribution selection, a technique that restricts the rate of inbreeding to a desired level while maximizing genetic gain. Alternatively, in the United States, genetic relationships were computed to predict the expected inbreeding level of future progeny from the mating of a random set of females and males, which were assumed to represent the breed population (VanRaden and Smith, 1999). This expected future inbreeding is estimated by halving the average genetic relationship of an animal to its potential mates. Similarly in 2003, Van Doormaal et al. (2003) developed an $\mathrm{R}$-value, which is the average genetic relationship computed for individual animals relative to the active females in a recent birth year. These R-values are publicly provided by the Canadian Dairy Network to producers to highlight bulls with low genetic relationship values to the current population, thus, further helping to reduce inbreeding. More recently, some authors have shown the applicability of controlling genomic inbreeding with genomic optimum contribution selection when using GS (Sonesson et al., 2012; Woolliams et al., 2015).

With the global adoption of GS, the annual level of inbreeding is increasing rapidly due to the higher turn-over of generations resulting from the shortened generation interval (Daetwyler et al., 2007). The rate of inbreeding is inversely proportional to $N_{e}$, a measure developed by Wright (1931) and commonly used as an indicator to evaluate genetic diversity for the purpose of genetic resource management and conservation. Effective population size has been estimated for different livestock species with ranges from 33 to 153 for dairy cattle (Stachowicz et al., 2011; Rodríguez-Ramilo et al., 2015; Doekes et al., 2018), 61 to 113 for pigs (Welsh et al., 2010; Uimari and Tapio, 2011), 38 to 675 for sheep (García-Gámez et al., 2012; Leroy et al., 2013), and 90 to 110 for goat (Mucha et al., 2015). These estimates are population specific and suggest that the $N_{e}$ are much smaller than the actual observed populations due to increased inbreeding coefficients $(\boldsymbol{F})$ caused by intense selection and genetic drift (small sub-populations). Before the advent of genomic information, rate of inbreeding and $N_{e}$ were estimated using pedigree information. However, pedigree inbreeding estimates are probabilities of having 2 alleles sampled randomly from a specific locus on a chromosome of a particular individual that descended from a given ancestor (Wright, 1922). These estimates are often imprecise due to incomplete or incorrect pedigree records, as well as the assumption that no relationship exists among individual animals in the base population; hence, they usually underestimate true inbreeding coefficients (Forutan et al., 2018). The availability of genomic data has presented researchers with the opportunity to more precisely identify actual DNA segments shared between individuals as opposed to expectations estimated from pedigree data. With genomic information, different methods have been proposed for the estimation of genomic inbreeding (VanRaden et al., 2011b; Yang et al., 2011; de Cara et al., 2013). Basically, 2 approaches are used in the calculation of genomic inbreeding: a marker-by-marker-based approach and a segment-based approach. The former can be estimated by observing the presence of excessive homozygosity (Yang et al., 2011), which is an indication of a departure from Hardy-Weinberg equilibrium resulting from inbreeding (Haldane, 1954). Similarly, the subtraction of 1 from the diagonal of the genomic relationship matrix has been used to estimate genomic inbreeding by VanRaden (2008) following the proposition from human studies (Leutenegger et al., 2003). The segment-based approach involves the estimation of inbreeding based on observing unbroken continuous stretches of homozygous alleles present in an individual as a result of inheriting this segment by descent from a common ancestor (Broman and Weber, 1999; McQuillan et al., 2008). These unbroken regions are often referred to as runs of homozygosity (ROH). The estimation of inbreeding coefficients from genomic data using segment-based rather than marker-by-markerbased methods have been shown to be closer to the true inbreeding coefficients (Forutan et al., 2018), as well as having higher correlation estimates with homozygous mutation load (Keller et al., 2011).

The objectives of this study were to (1) estimate the rate of inbreeding and $N_{e}$ in Holstein and Jersey dairy 
cattle using both pedigree and genomic information, (2) investigate the effect of GS on genetic diversity, (3) evaluate the changes in $N_{e}$ for specific time ranges, and (4) investigate the observed changes in unique haplotype counts over the studied time periods.

\section{MATERIALS AND METHODS}

Records used in this study were obtained from archived data of commercially raised Holstein and Jersey dairy cattle, and as such, no approval was required for animal use for experimental purposes from the Animal Care Committee unit of the University of Guelph.

\section{Pedigree Data}

Pedigree records were provided by the Canadian Dairy Network (Guelph, ON, Canada) and consisted of all known ancestors of the available genotyped animals, which included a total of 676,594 Holsteins and 304,676 Jerseys. Table 1 shows the numbers of records for each breed. For the 2 breeds, the base year of the pedigree was set to 1950, thus assuming that all individuals born at this time point were unrelated. The maximum pedigree depth was 34 and 26 generations for Holstein and Jersey breeds, respectively.

\section{Pedigree Completeness Index}

Incomplete pedigree results in the underestimation of mean inbreeding; therefore, the depth and completeness of pedigree is important in the estimation of inbreeding coefficients. A pedigree completeness index (PCI) was calculated for every individual in the pedigree going 5 generations back using the method developed by MacCluer et al. (1983) and implemented in Sargolzaei (2014). The depth of the pedigree was calculated separately for the contributions of paternal and maternal pathways. These contributions were used to calculate the PCI for each individual.

$$
C_{P a r}=\frac{1}{d} \sum_{i=1}^{d} a_{i}
$$

where $C_{P a r}$ is the contribution of parents (paternal and maternal estimated separately), $d$ is the number of generations traced back in the pedigree, and $a_{i}$ is the proportion of ancestors present in the $i$ th generation;

$$
\mathrm{PCI}=\frac{2 C_{S} C_{D}}{C_{S}+C_{D}}
$$

Table 1. Composition of pedigree records

\begin{tabular}{lrr}
\hline Item & Holstein & \multicolumn{1}{c}{ Jersey } \\
\hline No. of individuals & 676,594 & 304,676 \\
No. of sires & 58,602 & 22,604 \\
No. of dams & 449,114 & 214,592 \\
No. of individuals with known parents & 627,268 & 285,512 \\
No. of founders & 32,909 & 14,203 \\
Maximum number of generations & 34 & 26 \\
\hline
\end{tabular}

where $C_{S}$ and $C_{D}$ are the contribution indexes from paternal and maternal pathways, respectively. For both breeds, genotyped animals with a PCI of $90 \%$ or more were used for further downstream analyses. This was performed to ensure that the estimates from pedigree inbreeding are not underestimated, as missingness in pedigree information tends to downwardly bias inbreeding estimates.

\section{Genotype Data and Quality Control}

A total of 214,566 and 95,732 genotyped individuals were available for Holstein and Jersey, respectively. Of these animals, Holstein had 55,735 bulls and 158,831 cows genotyped whereas Jersey had 17,747 bulls and 77,985 cows genotyped, all of which were born between 1990 and 2018 inclusively. Figure 1 depicts the number of genotyped animals by year of birth. These animals were genotyped using low-, medium-, and high-density genotyping platforms. For Holstein, 48,356 animals were genotyped with density platforms between $7 \mathrm{~K}$ and 10K SNP, 56,654 animals had genotype density between $10 \mathrm{~K}$ and $50 \mathrm{~K}$, and the remaining were genotyped using $50 \mathrm{~K}$ and higher marker density platforms. For Jerseys, 27,128 animals had genotypes between $7 \mathrm{~K}$ and 10K, 46,551 animals were genotyped with SNP density panels between $10 \mathrm{~K}$ and $50 \mathrm{~K}$, and 22,053 animals had genotypes of $50 \mathrm{~K}$ SNP or higher. The proportions of bulls genotyped with $50 \mathrm{~K}$ or higher density chips and lower density chips for Holsteins were approximately 92 and $8 \%$, respectively, whereas $63 \%$ of cows were genotyped using $50 \mathrm{~K}$ or higher density panels and $37 \%$ were genotyped using lower density panels. Conversely for Jerseys, 44 and $56 \%$ of bulls were genotyped with $50 \mathrm{~K}$ or higher density panels and lower density panel, respectively. For Jersey cows, $82 \%$ were genotyped using lower density panels and 18\% were genotyped with $50 \mathrm{~K}$ or higher density panels. Genotypes from low density panels were imputed to medium density (50K) using FImpute v2.2 (Sargolzaei et al., 2014) and a subset of genotypes from high density panels present on the 50K density panels were used for analysis. Imputed genotypes had on average 99\% accuracy (allelic 
a)

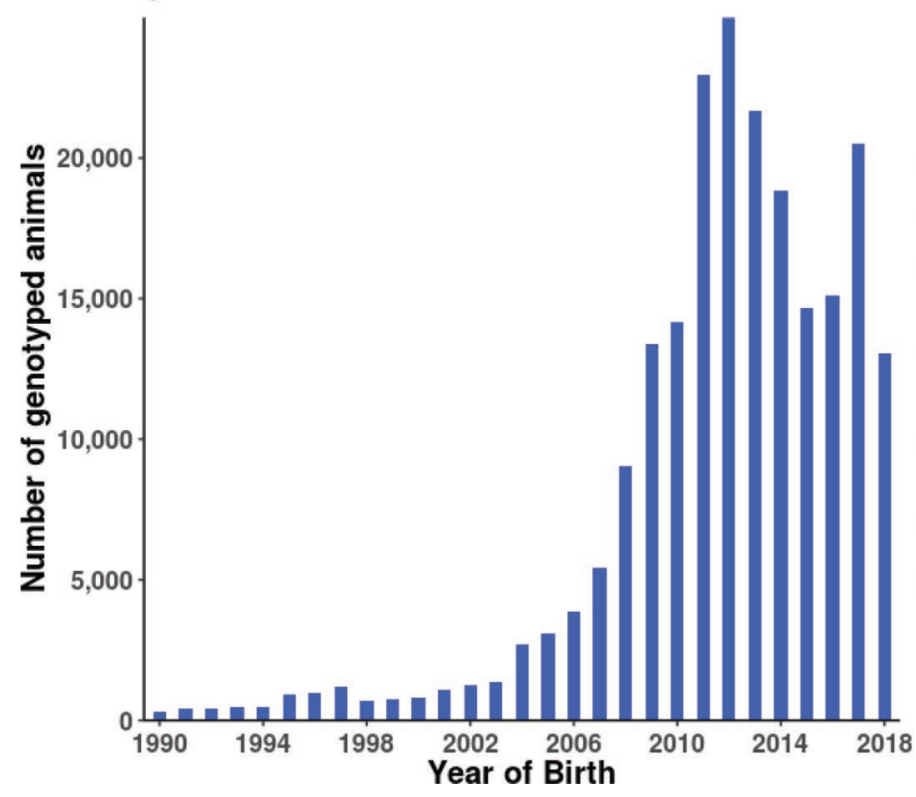

b)

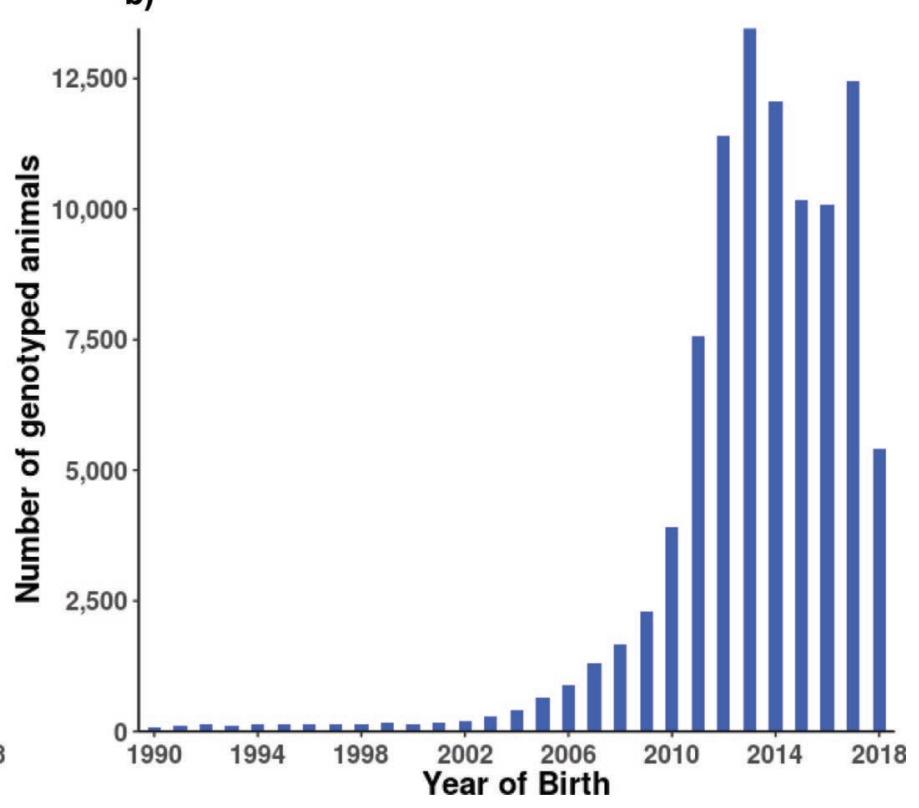

Figure 1. Distribution of genotyped animals per year of birth from 1990 to 2018. (a) Holsteins; (b) Jerseys.

$\mathrm{r}^{2}$ ) as a result of using pedigree information and a large reference population of 50,000 key ancestors with 50K genotypes. Parentage verification was performed for genotyped animals with an error rate of $2 \%$. Animals that had inconsistent genotypes with their parent and without an identified potential parent were removed. After quality control, a total of 205,755 and 89,238 animals were available for Holsteins and Jerseys, respectively. A total of 43,801 and 38,478 SNP genotypes for Holsteins and Jerseys, respectively, were retained for further analyses after filtering for quality control. Details of the parameters used in filtering have been reported by Wiggans et al. (2009). Briefly, only bi-allelic SNP with call rate $>0.95$, minor allele frequency $\geq 0.01$, and a difference less than 0.15 between observed and expected heterozygosity frequency were retained using SNP1101 (Sargolzaei, 2014).

\section{Haplotype Construction}

All genotypes available for further analyses were phased using a population-wide methodology as implemented in Beagle v5.0 (Browning and Browning, 2007). Phased genotypes were subsequently used to construct haplotypes using vcftools v0.1.16 (Danecek et al., 2011). Haplotypes were constructed using only SNP with a pairwise $\mathrm{r}^{2}>0.2$ and a fixed overlapping window size of 5 SNP markers. Unique haplotypes with a frequency less than $0.25 \%$ were excluded from further analyses.

\section{Changes in Unique Haplotype Counts}

Unique haplotype count changes were estimated by $\Delta c=c_{t}-c_{0}$, where $c_{0}$ and $c_{t}$ were the unique haplotype counts of different time periods. Three time periods were considered: (a) a period ranging from 1990 to 1999, (b) a period ranging from 2000 to 2009, and (c) a period ranging from 2010 to 2018. These periods were considered because they coincided with the major eras that witnessed the implementation of traditional BLUP evaluations, introduction of inbreeding controlling methods, and GS, respectively. Visualization of the changing pattern of the identified unique haplotype counts along the chromosomes were plotted against their physical position. The direction of change in the observed unique haplotype counts was investigated by computing the correlation coefficients between 3 different time periods (1990 to 1999, 2000 to 2009, and 2010 to 2018 ).

\section{Measures of Inbreeding}

Inbreeding coefficients $(F)$ were estimated using pedigree and genomic data. Pedigree inbreeding $\left(F_{P E D}\right)$ was calculated for each individual using the indirect algorithm developed by Colleau (2002) as implemented by Sargolzaei et al. (2005). Genomic inbreeding $\left(F_{R O H}\right)$ was calculated following the method proposed by McQuillan et al. (2008). To estimate $F_{R O H}$, ROH segments 
were identified using an overlapping sliding window approach that searches for homozygous segments from a long window covering the entire chromosome and gradually reduces to short windows, to capture both long and short ROH segments. SNP1101 software (Sargolzaei, 2014) was used to detect $\mathrm{ROH}$ using the following parameters: minimum window length was set at $1 \mathrm{Mb}$, minimum SNP in a window was 20, and an error rate of $0.1 \%$ was set to account for the presence of genotyping error. These parameters were selected based on a simulation study by Forutan et al. (2018), which reported these parameters as optimum because $F_{R O H}$ estimates were close to true inbreeding estimates in dairy cattle. In addition, $F_{R O H}$ was also detected using the sliding window approach implemented in PLINK v1.9 (Chang et al., 2015). With this approach the following criteria were used to define $\mathrm{ROH}$ : (1) a minimum of 20 consecutive homozygous SNP with at most 1 heterozygous allowed, (2) a minimum physical length of $1 \mathrm{Mb}$, (3) a maximum gap of $500 \mathrm{~kb}$ between 2 consecutive SNP, and (4) at least one SNP per $100 \mathrm{~kb}$. The genomic inbreeding for an individual was calculated as

$$
F_{\text {ROH }}=\frac{\sum_{i=1}^{n} L_{R O H_{i}}}{L_{A U T O}}
$$

where $L_{R_{O H}}$ is the length of the $i$ th $\mathrm{ROH}$ segment in bp, $n$ is the total number of detected $\mathrm{ROH}$, and $L_{\text {AUTO }}$ is the total length of the autosomes covered by the SNP in bp.

Given that $\mathrm{ROH}$ were identified using 2 different methods and to distinguish between the inbreeding estimates from the methods, $F_{R_{O} H_{-} S N P 1101}$ and $F_{\text {ROH_PLINK }}$ were used to signify inbreeding estimates from SNP1101 and PLINK, respectively. Also, genomic inbreeding was estimated using a marker-by-marker approach by subtracting one from the diagonal of the genomic relationship matrix $\mathbf{G}$, using a fixed allele frequency of 0.5 as proposed by VanRaden et al. (2011b) based on results showing higher correlations between pedigree inbreeding and genomic inbreeding. Marker-by-marker-based genomic inbreeding was estimated using the GCTA software (Yang et al., 2011). The genomic inbreeding for an individual was calculated as

$$
F_{G R M}=\mathbf{G}_{i i}-1,
$$

where $\mathbf{G}_{i i}$ is the diagonal of the genomic relationship matrix.

\section{Measures of Coancestry}

To assess the degree of relationships and nonrandom mating within breeds, the coefficients of coancestry $(f)$ were estimated using pedigree and genomic data. Pedigree coancestry $\left(f_{P E D}\right)$ was calculated using the indirect algorithm developed by Colleau (2002) as implemented by Sargolzaei et al. (2005) using SNP1101 (Sargolzaei, 2014). Genomic coancestry $\left(f_{S E G_{i j}}\right)$ was calculated following the method introduced by de Cara et al. (2013). Genomic coancestry is represented by shared genomic segments, which are identity by descent (IBD) between individual $i$ and individual $j$, and this is expected to be the $F_{R O H}$ of their offspring. These shared segments were identified by a sliding window approach, which moves SNP by SNP over the entire genome following the criteria used previously to identify $F_{R O H \_P L I N K}$. The genomic coancestry between 2 given individuals was calculated as

$$
f_{S E G_{i j}}=\frac{\sum_{k=1}^{n_{S E G_{i j}}} \sum_{a_{i}=1}^{2} \sum_{b_{j}=1}^{2} l_{S E G_{k}}\left(a_{i} b_{j}\right)}{4 L_{A U T O}},
$$

where $l_{S E G_{k}}\left(a_{i} b_{j}\right)$ is the length of the $k$ th shared segment measured over homolog $a$ of individual $i$ and homolog $b$ of individual $j, n_{S E G_{i j}}$ is the total number of detected segments shared between individual $i$ and individual $j$, and $L_{\text {AUTO }}$ is the total length of the autosomes covered by the SNP in bp.

\section{Rate of Inbreeding and Coancestry}

The rate of inbreeding $(\Delta F)$ and coancestry $(\Delta f)$ was calculated as the slope of the regression of the natural $\log$ of $\left(1-\overline{F_{t}}\right)$ and $\left(1-\overline{f_{t}}\right)$ on time and multiplying the slope by negative 1 (Hillestad et al., 2014; Doekes et al., 2018).

$$
y=\mu+\beta t+e,
$$

where $\overline{F_{t}}$ and $\overline{f_{t}}$ are the average inbreeding and coancestry coefficients, respectively, at a given year; $y=$ $\ln \left(1-\bar{F}_{t}\right) ; \mu=\ln \left(1-F_{0}\right) ; \beta=\ln (1-\Delta F), t$ is time in years, and $e$ is the error term. Similarly, $y=\ln (1-$ $\left.\bar{f}_{t}\right) ; \mu=\ln \left(1-f_{0}\right) ; \beta=\ln (1-\Delta f)$. Therefore, the $\Delta F$ $=1-\exp (\beta)$ and $\Delta f=1-\exp (\beta)$. 


\section{Measure of Linkage Disequilibrium}

Linkage disequilibrium (LD) was estimated in maternal haplotypes using $\mathrm{r}^{2}$, which is the squared correlation between pairs of alleles at 2 different loci (Hill and Robertson, 1968).

Only maternal haplotypes were used for the estimation of LD because the high selection intensity on the male line may reflect an over-representation of paternal haplotypes from the few selected sire families, which is not representative of the wider population of Holstein and Jersey in North America.

\section{Generation Interval and Effective Population Size}

The generation interval $(L)$ defined as the average age of parents when their offspring were calved and was calculated for all the 4 selection pathways (i.e., sire of bulls, dam of bulls, sire of cows, and dam of cows). The generation interval was estimated using the Pedig software package developed by Boichard (2002). The $N_{e}$ is defined as the number of breeding males and females in an idealized population that would result in the same inbreeding level observed in the real population (Wright, 1931). Effective population size $\left(N_{e}\right)$ is calculated as the reciprocal of twice the rate of inbreeding per generation (Falconer and Mackay, 1996). The rate of inbreeding per generation was determined as the rate of inbreeding per year $\left(\Delta F_{y}\right)$ times the generation interval $(L)$. The $N_{e}$ was calculated as follows:

$$
N_{e}=\frac{1}{2 L \Delta F_{y}}
$$

The future rate of inbreeding per generation was determined as the rate of coancestry $\left(\Delta f_{y}\right)$ times the generation interval $(L)$. The future effective population size $\left(N_{e_{f}}\right)$ was calculated as follows:

$$
N_{e_{f}}=\frac{1}{2 L \Delta f_{y}} .
$$

In addition, an approximate $N_{e}$ at a given point in the past was also estimated using the observed average LD $\left(\mathrm{r}^{2}\right)$ at a given genomic distance $c$, assuming no mutation as defined by Sved (1971):

$$
N_{e_{t}}=\frac{1}{4 c}\left(\frac{1}{r^{2}}-1\right)
$$

where $c$ is the marker distance in Morgans with an assumption of $1 \mathrm{Mb}=0.01 \mathrm{M}$. The effective population size $t$ generations ago $\left(N_{e_{t}}\right)$ was calculated using the relationship $t=1 / 2 c$ (Hayes et al., 2003).

\section{RESULTS}

The average PCI for both breeds had a pronounced increase from 1950 to 1986, after which the increase became gradual with a peak PCI of approximately $99 \%$ in 2018. For genotyped Holstein and Jersey animals, the average PCI was 99.69 and $99.00 \%$, respectively. The average PCI from 1990 to 2018 ranged from 99.34 to 99.97\% for Holsteins and 98.80 to $99.91 \%$ for Jerseys. The removal of genotyped animals with PCI less than $90 \%$ resulted in the exclusion of less than $2 \%$ of the animals, as most of the genotyped animals had PCI greater than $90 \%$. A slight decline in the PCI of genotyped animals was observed for both breeds with Holsteins having a more noticeable decline from 2010 to 2018 . This drop could be explained by the frequent use of unproven young sires in breeding schemes, which stems from the full implementation of GS. The shift in young genotyped bulls might have placed more emphasis on genomic information rather than pedigree information. Overall, for the 2 breeds, no year had an average PCI less than $97 \%$ (Figure 2).

Average inbreeding and coancestry coefficients for Holsteins and Jerseys using both pedigree and genomic data are shown in Table 2. The average inbreeding coefficients estimated from the marker-by-marker approach were approximately 2.5 and 2 times greater than the segment-based approach for Holsteins and Jerseys, respectively. The higher inbreeding coefficients estimated using marker-by-marker-based approach may have been inflated by the presence of alleles that are identical by state, which are not discriminated from IBD when using the marker-based approach. Generally, genomic inbreeding estimates often capture both the level of homozygosity and inbreeding; therefore, it is more important to monitor the trends in homozygosity over time than the absolute values estimated from genomic measures because this shows the increase in homozygosity resulting from inbreeding. Average coancestry coefficients tended to be slightly higher than average inbreeding coefficients for Holsteins and Jerseys. However, genomic coancestry measure showed higher coefficient than pedigree measure due to capturing both the level of homozygosity and relationships resulting from IBD.

Average annual inbreeding and coancestry levels are depicted in Figure 3 for both breeds. The inbreeding 

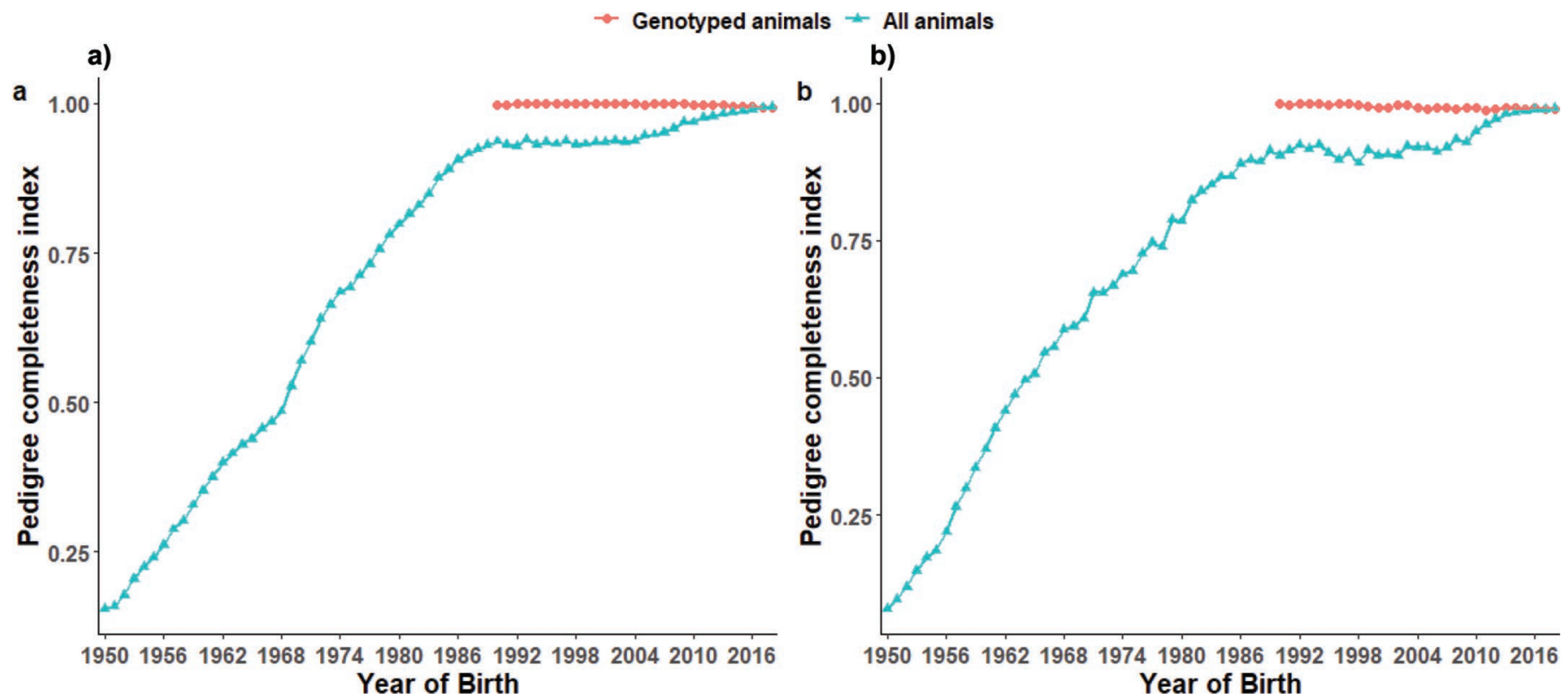

Figure 2. The average pedigree completeness index (PCI) of all animals in the pedigree from 1950 to 2018 and genotyped animals with birth year from 1990 to 2018. (a) Holsteins; (b) Jerseys.

level for Holstein had a steady rise from 1990, with a rapid increase occurring at the beginning of 2010 that continued through 2018. For Jerseys, the level of inbreeding increased from 1990 with some fluctuations, then in 2003 it declined before increasing again in 2011. The average annual coancestry for Holsteins and Jerseys followed a similar pattern to the average annual inbreeding observed using pedigree and genomic measures.

Generation intervals for all 4 pathways of selection are presented in Figure 4. The highest $L$ for Holsteins were found in 1990 with 8.08, 7.67, 5.74, and $4.49 \mathrm{yr}$ for sire of bulls, sire of cows, dam of bulls, and dam of cows, respectively. In 2009, $L$ began to decline more steeply and a noticeable drop occurred in the sire pathway. The lowest $L$ were $2.32,3.75,2.24$, and $3.25 \mathrm{yr}$

Table 2. Within-breed averages of pedigree inbreeding $\left(F_{P E D}\right)$, genomic inbreeding $\left(F_{R O H \_S N P 1101}, F_{R O H \_P L I N K}, F_{G R M}\right)$, pedigree coancestry $\left(f_{P E D}\right)$, and genomic coancestry $\left(f_{S E G}\right)$ coefficients for genotyped animals born between 1990 and 2018

\begin{tabular}{lrr}
\hline & \multicolumn{2}{c}{ Inbreeding $(\%) \pm \mathrm{SD}$} \\
\cline { 2 - 3 } Item & \multicolumn{1}{c}{ Holstein } & \multicolumn{1}{c}{ Jersey } \\
\hline$F_{P E D}$ & $7.74 \pm 2.22$ & $7.20 \pm 2.48$ \\
$F_{R O H \_S N P 1101}$ & $13.61 \pm 3.41$ & $21.16 \pm 3.46$ \\
$F_{\text {ROH_PLINK }}$ & $15.64 \pm 3.38$ & $22.54 \pm 3.39$ \\
$F_{\text {GRM }}$ & $31.40 \pm 2.72$ & $42.62 \pm 2.55$ \\
$f_{P E D}$ & $8.33 \pm 3.13$ & $9.23 \pm 3.69$ \\
$f_{S E G}$ & $15.84 \pm 4.48$ & $23.46 \pm 4.49$ \\
\hline
\end{tabular}

for sire of bulls, sire of cows, dam of bulls, and dam of cows, respectively, in 2016. In Jerseys a similar decline in $L$ was evident in 2009 mostly for the sire and dam of bulls pathways. Mostly, the highest $L$ in Jersey were 8.18, 6.91, and $4.24 \mathrm{yr}$ in 1990 for sire of bulls, sire of cows, and dam of cows, respectively, with the exception of the dam of bulls having the highest $L$ of 5.52 in 1992. The lowest $L$ were $3.17,3.47,2.86$, and $3.00 \mathrm{yr}$ for sire of bulls, sire of cows, dam of bulls, and dam of cows, respectively, in 2017.

Correlations between the different inbreeding measures within year are presented in Figure 5. The average correlation coefficients ranged from 0.70 to 0.97 for Holsteins and 0.61 to 0.97 for Jerseys. Correlations followed a declining trend for both Holsteins and Jerseys; however, for Holsteins a steady increase occurred from 2010. The correlation coefficients between $F_{R O H}$ and $F_{G R M}$ were consistently above 0.90 . The highest correlation between pedigree and genomic measure was 0.79 and 0.76 for Holsteins and Jerseys, respectively.

The rates of inbreeding and coancestry per year and per generation and their respective $N_{e}$ for the 1990-2018 period are presented in Table 3 . In addition, the rate of inbreeding and coancestry per year and per generation for the 3 time periods considered in this study are depicted in Figure 6 . The highest $\Delta F_{P E D}, \Delta F_{R O H \_S N P 1101}$, $\Delta F_{R O H_{P} P L I N K}, \Delta F_{G R M}, \Delta f_{P E D}$, and $\Delta f_{S E G}$ per generation were observed in the period between 2010 and 2018 for Holsteins, with 1.19, 1.95, 2.06, 2.01, 0.97, and 1.28\%, respectively (Figure 6). Hence, the $N_{e}$ for this period 
were lowest at $42,26,24,25,52$, and 39 animals for Holsteins. For Jerseys, the highest rate of inbreeding and coancestry per generation was observed between 1990 and 1999 and ranged from 1.03 to $1.47 \%$, which in turn resulted in an $N_{e}$ that ranged from 34 to 49 animals. In the period between 2000 and 2009, Holsteins had the lowest $\Delta F$ per generation at $0.37 \%$ for pedigree, 0.51 and $0.56 \%$ for the segment-based approaches, and $0.40 \%$ for the marker-by-marker approach, thus having a high $N_{e}$ of $136,99,89$, and 124 for measures based on pedigree, segment, and marker-by-marker, respectively. Equivalently, the $\Delta f$ was lowest for the period between
2000 and 2009 for Holsteins, with $0.90 \%$ for pedigree and $1.17 \%$ for the segment-based approach, which corresponds to an $N_{e}$ of 56 and 43, respectively. Similarly in Jerseys, the lowest $\Delta F$ per generation was observed in the period between 2000 and 2009, with a negative $\Delta F$ for all the considered measures indicating a reduction in inbreeding level for that period. However, the $\Delta f_{P E D}$ and $\Delta f_{S E G}$ per generation for the period between 2000 and 2009 was slightly above zero, indicating the existence of genetic and genomic relationship between animals. The $\Delta F_{P E D}, \Delta F_{R O H_{\_} S N P 1101}, \Delta F_{R O H \_P L I N K}$, $\Delta F_{G R M}, \Delta f_{P E D}$, and $\Delta f_{S E G}$ per generation obtained for
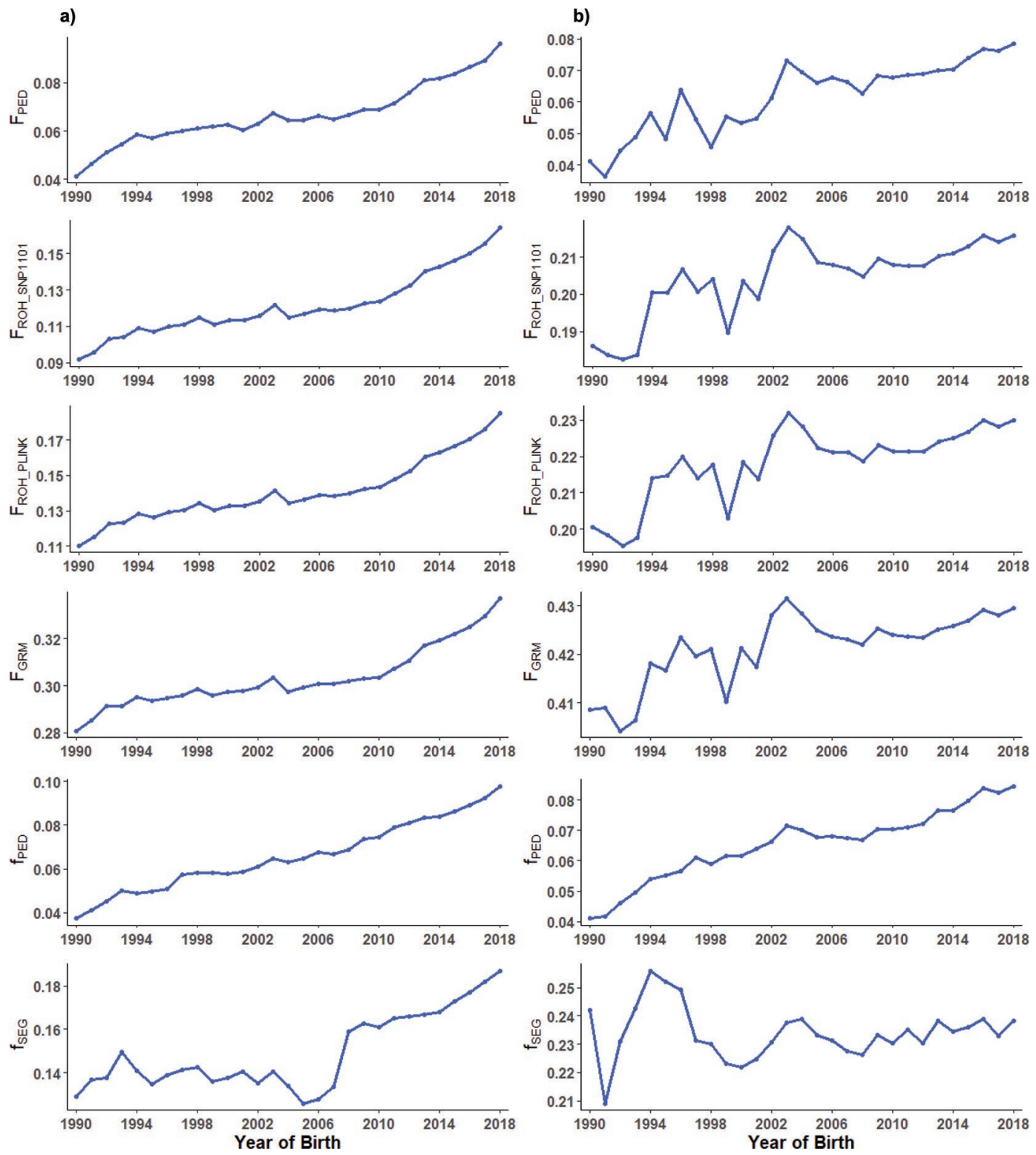

Figure 3. Average annual inbreeding and coancestry trends for genotyped animals by birth year from 1990 to 2018 using pedigree $\left(F_{P E D}\right.$, $\left.f_{P E D}\right)$, segment-based $\left(F_{R O H \_S N P 1101}, F_{R O H \_P L I N K}, f_{S E G}\right)$, and marker-by-marker-based $\left(F_{G R M}\right)$ genomic measures. (a) Holsteins; (b) Jerseys. 
the overall 29-yr time period were $0.75,1.10,1.16,1.02$, 0.98 , and $0.98 \%$ for Holsteins and $0.67,0.62,0.63,0.59$, 0.73 , and $0.78 \%$ for Jerseys, respectively (Table 3 ). This translates to an $N_{e}$ of $66,46,43,49,51$, and 51 for Holsteins and 75, 81, 80, 85, 68, and 62 for Jerseys, respectively. In Holsteins, genomic $\Delta F$ was higher than pedigree $\Delta F$ for all the periods examined; however, for Jerseys the converse was the case, with higher $\Delta F$ observed using pedigree, with the exception of the period between 1990 and 1999, which had higher genomic $\Delta F$. Comparatively, the $N_{e}$ estimated from the extent of LD decay 5 generations ago was 58 for Holsteins and 120 for Jersey. The $N_{e}$ estimated from 5 to 100 generations ago for the 2 breeds using LD are presented in Figure 7. The decay of LD per chromosome is reported in Supplemental Figure S1 (https://doi.org/10.3168/jds .2019-18013).

The number of unique haplotype counts varied substantially across the chromosomes and ranged from 3 to 32. More specifically, chromosome 1, 8, and 29 had regions with a higher number of unique haplotypes, whereas chromosome 6,7 , and 10 had regions with fewer unique haplotypes for Holsteins. Conversely, for Jersey, chromosome 6, 7, and 1 showed a higher number of unique haplotypes with other chromosomes showing fewer unique haplotypes. Tables 4 and 5 shows the number of unique haplotype counts per chromosome for 3 different periods. Changes in the number of unique haplotypes within chromosomes for 1990-1999 and 2010-2018 time periods are presented in Supplemental Figure S2 (https://doi.org/10.3168/jds.2019-18013).
These changes ranged from -5 to 12 for both Holsteins and Jersey populations, with negative and positive values indicating loss and gain of haplotypes, respectively. The direction of change in haplotype counts was compared between three 10-yr periods from 1990 to 2018 and were estimated to range from -0.26 to 0.84 (Table 6).

\section{DISCUSSION}

This study investigated the changes that occurred in the $N_{e}$, rate of inbreeding and coancestry, and generation interval before and after the adoption of GS, after assessing the quality and depth of the pedigree data of the genotyped animals. The PCI going 5 generations back was high for both breeds, suggesting that the pedigree data available was suitable for the estimation of inbreeding coefficients and loss of genetic diversity. One consequence of GS is the dramatic reduction in $L$ for most selection pathways as predicted by Schaeffer (2006), and this was evident in this study. For Holsteins, the average $L$ before the implementation of GS was approximately $7 \mathrm{yr}$ for the sire pathways, whereas the dam pathways had a $L$ of around $4 \mathrm{yr}$, which was a result of the time taken to prove sires following progeny testing. In the most recent $9 \mathrm{yr}$ coinciding with the implementation of GS, percentage decreases of $63,45,40$, and $18 \%$ were observed in the sire of bull, sire of cow, dam of bull, and dam of cow pathways, respectively, with similar reductions reported by García-Ruiz et al. (2016). Jerseys had a lower $L$ reduction compared with
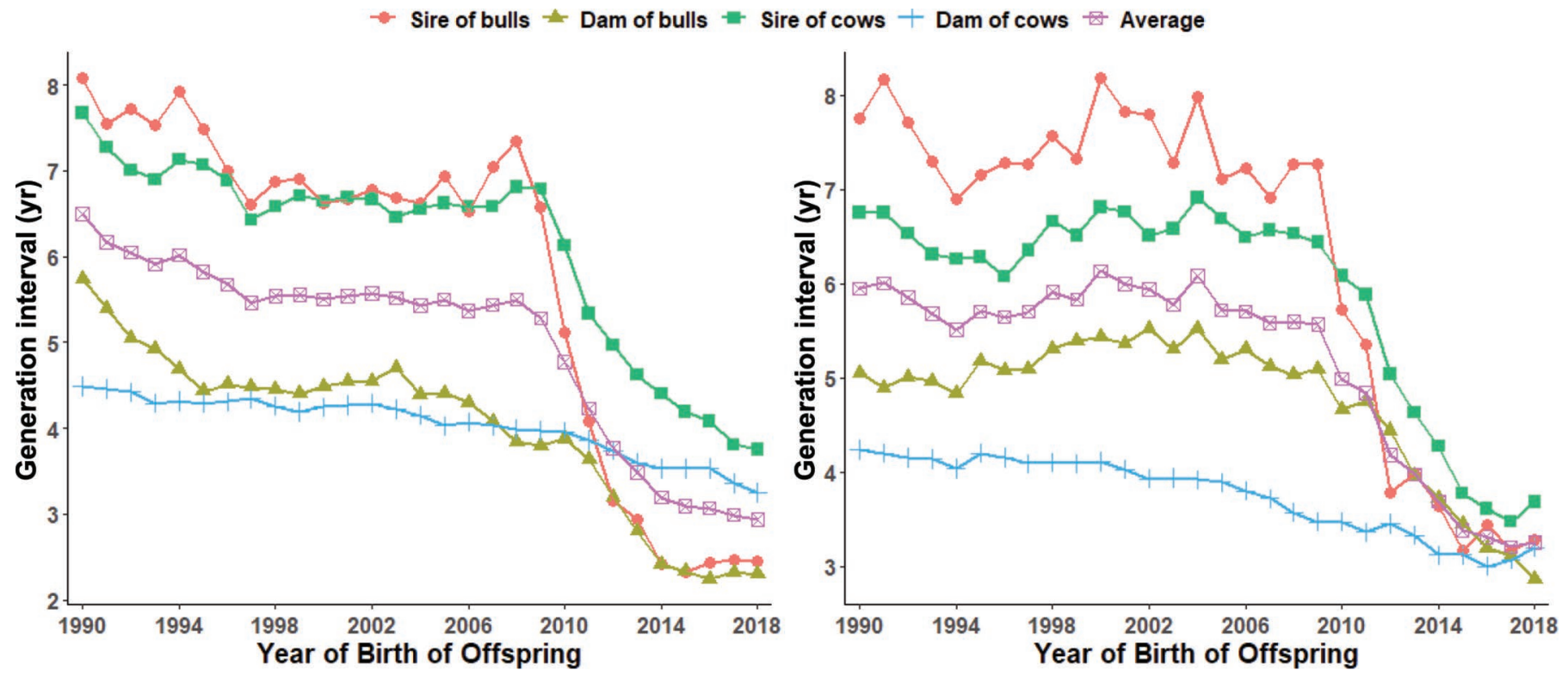

Figure 4. Within-breed average generation interval per year of birth from 1990 to 2018 for the 4 pathways of selection (left $=$ Holsteins; right $=$ Jerseys). 


\section{- $\boldsymbol{F}_{P E D} \& \boldsymbol{F}_{\text {ROH_SNP1101 }}$ \\ $-F_{P E D} \& F_{\text {ROH_PLINK }}$

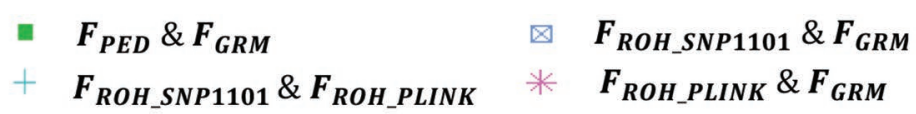

a)

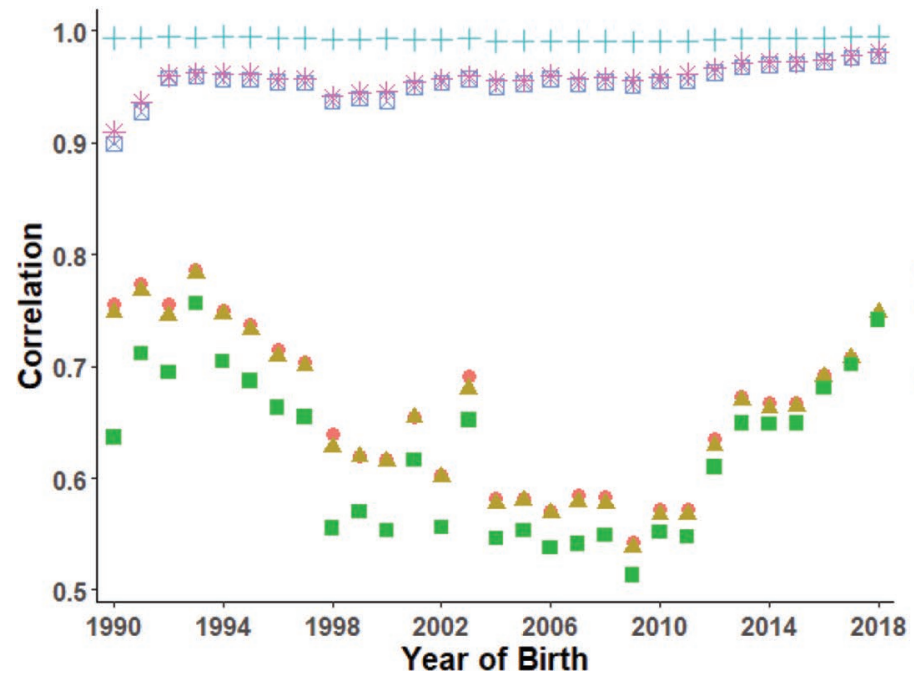

b)

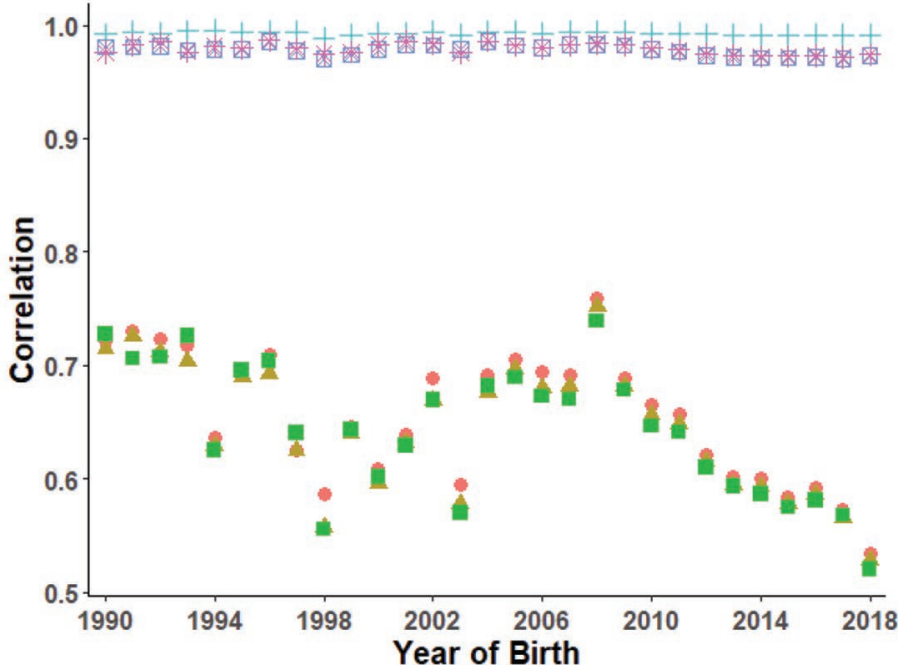

Figure 5. Within-year correlations between pedigree $\left(F_{P E D}\right)$, segment-based $\left(F_{R O H \_S N P 1101}, F_{R O H \_P L I N K}\right)$, and marker-by-marker-based $\left(F_{G R M}\right)$ genomic measures of inbreeding per year of birth. (a) Holsteins; (b) Jerseys.

Holsteins with 55, 43, 44, and $8 \%$ drop in the sire of bull, sire of cow, dam of bull, and dam of cow pathways, respectively. From 1990 to 2009, the average $L$ over all the 4 pathways was 5.67 and 5.79 yr for Holsteins and Jerseys, respectively. After 2009, the average of all pathways rapidly dropped to 3.51 and 3.87 , translating to approximately 38 and $33 \%$ drops in Holsteins and Jerseys, respectively, within the first decade of implementing GS. Similarly, García-Ruiz et al. (2016) reported a $37 \%$ reduction in $L$ for US Holstein data. There was a difference of approximately $1.5 \mathrm{yr}$ between Holsteins and Jerseys after 2009, likely indicating that the uptake of GS was more intense in Holsteins than in Jerseys.

The correlation coefficients between pedigree and genomic inbreeding measures reported in the present study are in accordance with previous studies (VanRaden et al., 2011b; Purfield et al., 2012; Zhang et al., 2015; Forutan et al., 2018), which ranged from 0.47 to 0.82 . Differences between studies may be due to population sizes and the method employed in identifying ROH. For Holsteins, the correlations between $F_{P E D}$ and $F_{R O H}$ decreased to 0.54 from 0.79 between 1993 and 2009, whereas for Jerseys a more pronounced decrease from 0.76 to 0.53 was observed from 2008 to 2018. This decline could be explained as a consequence of the ability of genomic measures to capture the Mendelian sampling term not captured by pedigree measures.

An important indicator in assessing the loss of genetic diversity is the rate of inbreeding and coancestry. Several studies have estimated the $\Delta F$ and $\Delta f$ for different dairy cattle populations using both pedigree and ge-

Table 3. Within-breed estimation of pedigree rate of inbreeding $\left(\Delta F_{P E D}, \%\right)$, genomic rate of inbreeding $\left(\Delta F_{R O H_{-} S N P 1101}, \Delta F_{R O H \_P L I N K}, \Delta F_{G R M}, \%\right)$, pedigree rate of coancestry $\left(\Delta f_{P E D}, \%\right)$, and genomic rate of coancestry $\left(\Delta f_{S E G}, \%\right)$ per year and per generation and their respective effective population size $\left(N_{e}\right)$ from 1990 to 2018

\begin{tabular}{|c|c|c|c|c|c|c|}
\hline \multirow[b]{2}{*}{ Item } & \multicolumn{3}{|c|}{ Holstein } & \multicolumn{3}{|c|}{ Jersey } \\
\hline & Year & Generation & $N_{e}$ & Year & Generation & $N_{e}$ \\
\hline $\begin{array}{l}\Delta F_{P E D}{ }^{1} \\
\Delta F_{R O H \_S N P 1101}^{1} \\
\Delta F_{R O H}{ }_{1} P L I N K \\
\Delta F_{G R M} \\
\Delta f_{P E D} \\
\Delta f_{S E G}{ }_{1}\end{array}$ & $\begin{array}{l}0.15 \\
0.22 \\
0.23 \\
0.20 \\
0.20 \\
0.20\end{array}$ & $\begin{array}{l}0.75 \\
1.10 \\
1.16 \\
1.02 \\
0.98 \\
0.98\end{array}$ & $\begin{array}{l}66 \\
46 \\
43 \\
49 \\
51 \\
51\end{array}$ & $\begin{array}{l}0.13 \\
0.12 \\
0.12 \\
0.11 \\
0.14 \\
0.15\end{array}$ & $\begin{array}{l}0.67 \\
0.62 \\
0.63 \\
0.59 \\
0.73 \\
0.78\end{array}$ & $\begin{array}{l}75 \\
81 \\
80 \\
85 \\
68 \\
64\end{array}$ \\
\hline
\end{tabular}

${ }^{1}$ Standard errors for the estimation of the rate of inbreeding were $<0.0001$. 

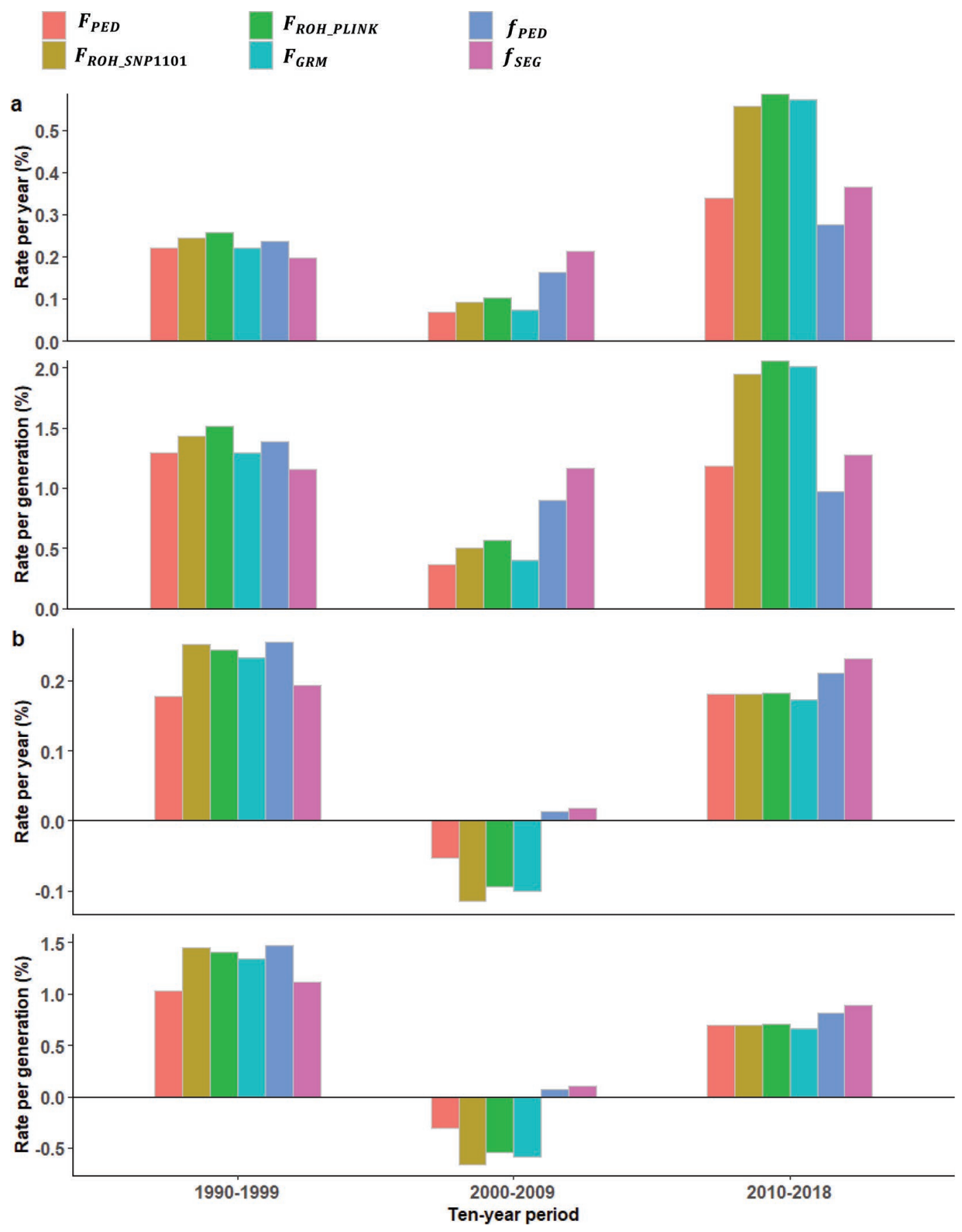

Figure 6 . Rate of inbreeding and coancestry based on pedigree $\left(F_{P E D}, f_{P E D}\right)$, segment $\left(F_{R O H \_S N P 1101}, F_{R O H \_P L I N K}, f_{S E G}\right)$, and marker-by-marker $\left(F_{G R M}\right)$ genomic measures within 10-yr periods from 1990 to 2018. (a) Holsteins; (b) Jerseys.

nomic data from different time periods yielding ranges from 0.32 to $2.80 \%$ for $\Delta F$ per generation and 0.42 to $1.52 \%$ for $\Delta f$ per generation (Sørensen et al., 2005 ; Stachowicz et al., 2011; Doekes et al., 2018). A notable similarity between those studies and the present study is the change in $\Delta F$ and $\Delta f$ across time periods; however, a constant $\Delta F$ across time was reported for the Spanish
Holstein population (Rodríguez-Ramilo et al., 2015). More precisely, the $\Delta F$ and $\Delta f$ in the current study was calculated for the 3 different time periods (1990-1999, 2000-2009, and 2010-2018). Based only on pedigree data, Stachowicz et al. (2011) reported $1.52 \%$ as the $\Delta F$ and $\Delta f$ per generation for the period between 1990 to 1999 inclusively for the Canadian Holstein popula- 

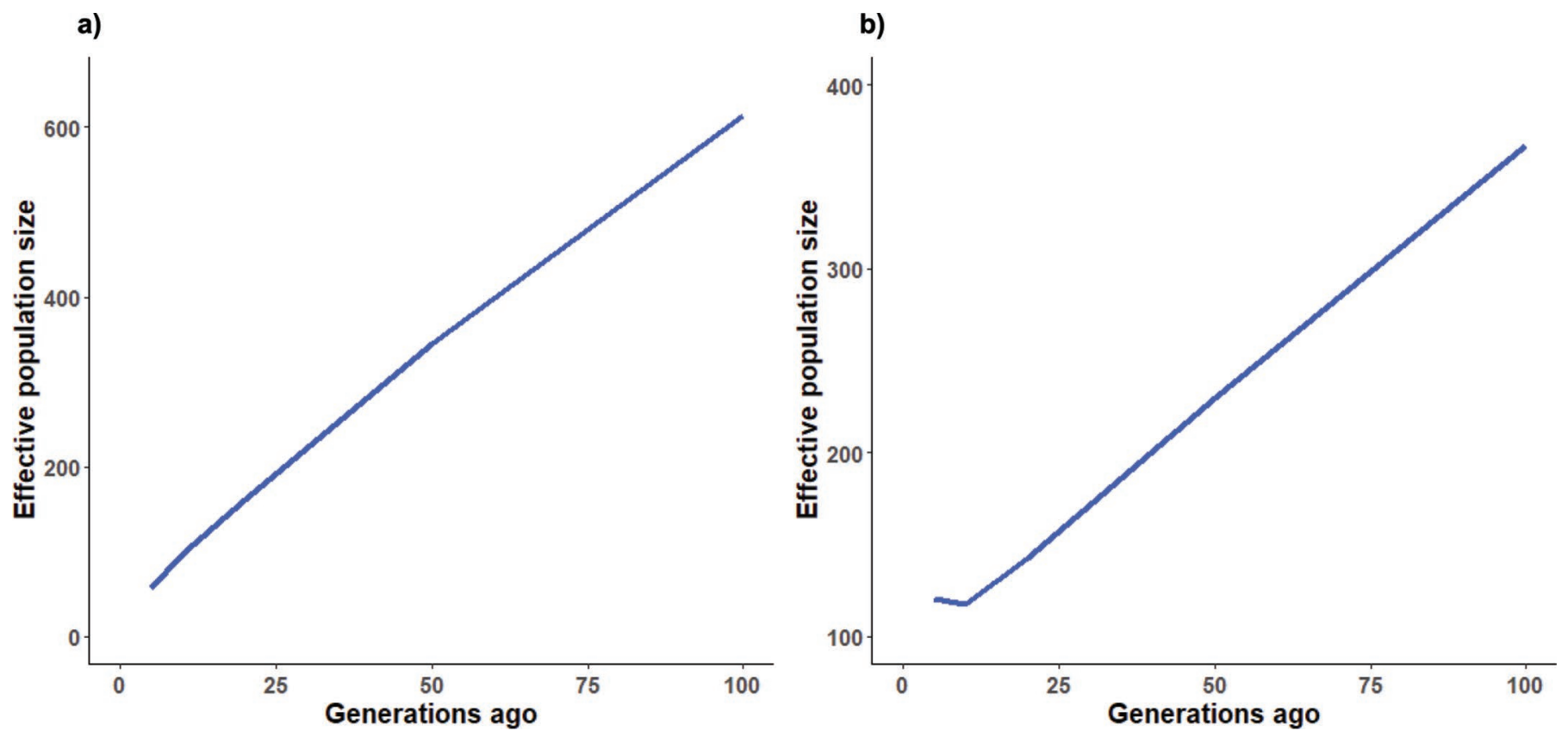

Figure 7. Effective population size estimated from linkage disequilibrium from 5 to 100 generations ago. (a) Holsteins; (b) Jerseys.

tion. This estimate is close to the $1.30,1.44,1.51,1.30$, 1.38 , and $1.16 \%$ per generation reported here for $\Delta F_{P E D}$, $\Delta F_{R O H \_S N P 1101}, \Delta F_{R O H \_P L I N K}, \Delta F_{G R M}, \Delta f_{P E D}$, and $\Delta f_{S E G}$, respectively, for the North American Holstein population. The popularity and implementation of individual animal model BLUP evaluations across the globe during this period (Simm, 2000) may have resulted in the high estimates of $\Delta F$ and $\Delta f$. With the awareness of the high rate of inbreeding during the early and late 1990s, researchers in North America and Europe developed methods such as R-values (Van Doormaal et al., 2003), genetic relationships (VanRaden and Smith, 1999), and optimum contribution selection (Meuwissen, 1997), to constrain the $\Delta F$ to a minimal level. The resulting effect was a drop in $\Delta F$ to $0.37,0.51,0.56$, and $0.40 \%$ for the period from 2000 to 2009 using pedigree, segmentbased, and marker-by-marker-based data, respectively, as shown in the current study. Although a substantial drop in the $\Delta F$ was observed in this period, the $\Delta f$ was relatively high at 0.90 and $1.17 \%$ for pedigree and genomic measures, respectively, therefore suggesting that there is a considerable presence of genetic and genomic relationships between animals. The differences between $\Delta F$ and $\Delta f$ support the effectiveness of the methods implemented to constrain the level of inbreeding by avoiding the mating of closely related animals.

Since the implementation of GS there has been an increase in the $\Delta F$ with $1.19,1.95,2.05$, and $2.01 \%$ for the 2010 and 2018 period, which are similar to the figures reported in Doekes et al. (2018) for Dutch
Holstein-Friesian population using pedigree, segmentbased, and marker-by-marker-based data, respectively. Likewise, the $\Delta f$ per generation increased to 0.97 and $1.28 \%$ for the 2010 to 2018 period.

In Jerseys, a similar pattern for the $\Delta F$ and $\Delta f$ was observed for comparable periods as seen with Holsteins. The $\Delta F$ and $\Delta f$ for the time periods (1990-1990, 20002009, and 2010-2018) investigated are presented on Figure 6 . The first period was the period that captured the implementation of traditional BLUP and this shows an increase in the rate of inbreeding. Subsequently, a drop in the second period from the first period was observed with Jerseys having sub-zero rate of inbreeding and slightly positive rate of coancestry. This decline could be attributable to the introduction of methods to constrain the rate of inbreeding developed at that time point. In 2010-2018, $\Delta F$ showed more than a 2-fold increase in both breeds in reference to the previous period. Overall, the trends in $\Delta F$ from 2010 to 2018 shows that GS leads to a faster increase in the yearly rate of inbreeding when compared with traditional BLUP as predicted by Daetwyler et al. (2007).

The $N_{e}$ reported in this study ranged from 43 to 85 for Holsteins and Jerseys, respectively (Table 3). These ranges were within the ranges previously reported $(\mathrm{S} \varnothing-$ rensen et al., 2005; Sargolzaei et al., 2008; Stachowicz et al., 2011). A critical $N_{e}$ at which the population begins to lose fitness and viability in the long term was stipulated at below 50 animals by FAO (2015). This critical $N_{e}$ may cause selection to drive a deleterious mutation 
Table 4. Summary statistics of unique haplotype counts within a 10-yr period, differences between these periods, and the rate of change between the periods for Holsteins

\begin{tabular}{|c|c|c|c|c|c|c|c|}
\hline BTA & $1990-1999^{1}$ & $2000-2009^{2}$ & $2010-2018^{3}$ & $\Delta c_{1}^{4}$ & $\Delta c_{2}^{5}$ & $\% \Delta c_{1}^{6}$ & $\% \Delta c_{2}^{6}$ \\
\hline 1 & 4,648 & 6,460 & 6,293 & 1,812 & -167 & 38.98 & -2.59 \\
\hline 2 & 4,219 & 5,737 & 5,376 & 1,518 & -361 & 35.98 & -6.29 \\
\hline 3 & 3,535 & 4,933 & 4,865 & 1,398 & -68 & 39.55 & -1.38 \\
\hline 4 & 3,529 & 5,013 & 4,851 & 1,484 & -162 & 42.05 & -3.23 \\
\hline 5 & 3,203 & 4,383 & 4,218 & 1,180 & -165 & 36.84 & -3.76 \\
\hline 6 & 3,626 & 5,064 & 4,886 & 1,438 & -178 & 39.66 & -3.52 \\
\hline 7 & 3,403 & 4,589 & 4,303 & 1,186 & -286 & 34.85 & -6.23 \\
\hline 8 & 3,343 & 4,757 & 4,604 & 1,414 & -153 & 42.30 & -3.22 \\
\hline 9 & 2,731 & 3,791 & 3,658 & 1,060 & -133 & 38.81 & -3.51 \\
\hline 10 & 3,441 & 4,678 & 4,501 & 1,237 & -177 & 35.95 & -3.78 \\
\hline 11 & 3,221 & 4,493 & 4,339 & 1,272 & -154 & 39.49 & -3.43 \\
\hline 12 & 2,325 & 3,181 & 3,150 & 856 & -31 & 36.82 & -0.97 \\
\hline 13 & 2,651 & 3,537 & 3,413 & 886 & -124 & 33.42 & -3.51 \\
\hline 14 & 2,722 & 3,662 & 3,508 & 940 & -154 & 34.53 & -4.21 \\
\hline 15 & 2,313 & 3,303 & 3,145 & 990 & -158 & 42.80 & -4.78 \\
\hline 16 & 2,427 & 3,284 & 3,026 & 857 & -258 & 35.31 & -7.86 \\
\hline 17 & 2,376 & 3,263 & 3,167 & 887 & -96 & 37.33 & -2.94 \\
\hline 18 & 1,814 & 2,550 & 2,484 & 736 & -66 & 40.57 & -2.59 \\
\hline 19 & 2,032 & 2,807 & 2,700 & 775 & -107 & 38.14 & -3.81 \\
\hline 20 & 2,458 & 3,223 & 3,098 & 765 & -125 & 31.12 & -3.88 \\
\hline 21 & 2,045 & 2,825 & 2,715 & 780 & -110 & 38.14 & -3.89 \\
\hline 22 & 1,870 & 2,619 & 2,475 & 749 & -144 & 40.05 & -5.50 \\
\hline 23 & 1,673 & 2,341 & 2,212 & 668 & -129 & 39.93 & -5.51 \\
\hline 24 & 1,905 & 2,600 & 2,496 & 695 & -104 & 36.48 & -4.00 \\
\hline 25 & 1,542 & 2,132 & 2,020 & 590 & -112 & 38.26 & -5.25 \\
\hline 26 & 1,573 & 2,202 & 2,111 & 629 & -91 & 39.99 & -4.13 \\
\hline 27 & 1,422 & 1,976 & 1,891 & 554 & -85 & 38.96 & -4.30 \\
\hline 28 & 1,403 & 1,948 & 1,874 & 545 & -74 & 38.85 & -3.80 \\
\hline 29 & 1,620 & 2,275 & 2,196 & 655 & -79 & 40.43 & -3.47 \\
\hline Total & 75,070 & 103,626 & 99,575 & 28,556 & $-4,051$ & $38.04^{7}$ & $-3.91^{7}$ \\
\hline
\end{tabular}

\footnotetext{
${ }^{1}$ Animals with birth year from 1990 to 1999.

${ }^{2}$ Animals with birth year from 2000 to 2009 .

${ }^{3}$ Animals with birth year from 2010 to 2018 .

${ }^{4}$ Differences between 2000-2009 and 1990-1999.

${ }^{5}$ Differences between 2010-2018 and 2000-2009.

${ }^{6}$ Percentage rate of change.

${ }^{7}$ Overall mean.
}

to fixation, thus reducing the fitness of the population. At present, the overall $N_{e}$ from 1990 to 2018 stands at 66, 46, 43, and 49 for Holsteins and 75, 81, 80, and 85 for Jerseys with pedigree, segment-based, and markerby-marker data, respectively. In addition, the predicted future $N_{e}$ was 51 and 51 for Holsteins and 68 and 64 for Jerseys using pedigree and genomic measures, respectively. Furthermore, the estimated $N_{e} 5$ generations ago based on LD was 58 and 120 for Holsteins and Jerseys, respectively, which is within the range estimated from the rate of inbreeding and coancestry. For proper management of genetic resources and reduction in loss of genetic diversity, novel approaches such as genomic optimum contribution selection are to be developed to forestall any further reduction in $N_{e}$ and, hence, loss of fitness.

Genomic inbreeding measures are closer to the true inbreeding rate (Forutan et al., 2018) and show higher correlations to genetic mutation load, which is a mea- sure of fitness (Keller et al., 2011). Therefore, the $\Delta F$, $\Delta f$, and $N_{e}$ estimated from genomic data are likely a good reflection of the actual $\Delta F, \Delta f$, and $N_{e}$, suggesting that Holsteins are currently at a critical $N_{e}$. However, the small $N_{e}$ estimated in this present study is expected given that only genotyped animals were used for the analyses and also the inclusion of bull genotypes, which are heavily selected, consequently determined the high rate of estimated inbreeding. In contrast to Holsteins, Jerseys had higher $N_{e}$ and lower $\Delta F$ for all periods investigated and particularly evident was that the pedigree measure of $N_{e}$ had lower values than those estimated from genomic measures. This could suggest that the loss of genetic diversity in Holsteins is attributable to directional selection causing markers surrounding QTL to increase to high frequencies in the population, a phenomenon known as hitchhiking (Smith and Haigh, 1974), whereas it is likely that the less intense GS implemented in Jerseys allows for more genetic di- 
Table 5. Summary statistics of unique haplotype counts within a 10-yr period, differences between these periods, and the rate of change between the periods for Jerseys

\begin{tabular}{|c|c|c|c|c|c|c|c|}
\hline BTA & $1990-1999^{1}$ & $2000-2009^{2}$ & $2010-2018^{3}$ & $\Delta c_{1}^{4}$ & $\Delta c_{2}^{5}$ & $\% \Delta c_{1}^{6}$ & $\% \Delta c_{2}^{6}$ \\
\hline 1 & 2,755 & 3,775 & 3,673 & 1,020 & -102 & 37.02 & -2.70 \\
\hline 2 & 2,388 & 3,193 & 3,002 & 805 & -191 & 33.71 & -5.98 \\
\hline 3 & 2,065 & 2,884 & 2,844 & 819 & -40 & 39.66 & -1.39 \\
\hline 4 & 2,208 & 3,129 & 2,975 & 921 & -154 & 41.71 & -4.92 \\
\hline 5 & 1,891 & 2,590 & 2,508 & 699 & -82 & 36.96 & -3.17 \\
\hline 6 & 2,111 & 2,920 & 2,795 & 809 & -125 & 38.32 & -4.28 \\
\hline 7 & 2,037 & 2,738 & 2,558 & 701 & -180 & 34.41 & -6.57 \\
\hline 8 & 2,010 & 2,879 & 2,719 & 869 & -160 & 43.23 & -5.56 \\
\hline 9 & 1,765 & 2,450 & 2,383 & 685 & -67 & 38.81 & -2.73 \\
\hline 10 & 1,948 & 2,634 & 2,549 & 686 & -85 & 35.21 & -3.23 \\
\hline 11 & 2,044 & 2,854 & 2,756 & 810 & -98 & 39.63 & -3.43 \\
\hline 12 & 1,627 & 2,232 & 2,197 & 605 & -35 & 37.19 & -1.57 \\
\hline 13 & 1,544 & 2,060 & 1,981 & 516 & -79 & 33.42 & -3.83 \\
\hline 14 & 1,666 & 2,256 & 2,152 & 590 & -104 & 35.41 & -4.61 \\
\hline 15 & 1,423 & 2,038 & 1,952 & 615 & -86 & 43.22 & -4.22 \\
\hline 16 & 1,517 & 2,052 & 1,891 & 535 & -161 & 35.27 & -7.85 \\
\hline 17 & 1,530 & 2,050 & 1,990 & 520 & -60 & 33.99 & -2.93 \\
\hline 18 & 1,139 & 1,612 & 1,565 & 473 & -47 & 41.53 & -2.92 \\
\hline 19 & 1,261 & 1,735 & 1,666 & 474 & -69 & 37.59 & -3.98 \\
\hline 20 & 1,359 & 1,776 & 1,721 & 417 & -55 & 30.68 & -3.10 \\
\hline 21 & 1,250 & 1,740 & 1,672 & 490 & -68 & 39.2 & -3.91 \\
\hline 22 & 1,136 & 1,591 & 1,499 & 455 & -92 & 40.05 & -5.78 \\
\hline 23 & 1,069 & 1,481 & 1,401 & 412 & -80 & 38.54 & -5.40 \\
\hline 24 & 1,146 & 1,563 & 1,520 & 417 & -43 & 36.39 & -2.75 \\
\hline 25 & 963 & 1,352 & 1,270 & 389 & -82 & 40.39 & -6.07 \\
\hline 26 & 967 & 1,353 & 1,294 & 386 & -59 & 39.92 & -4.36 \\
\hline 27 & 889 & 1,239 & 1,185 & 350 & -54 & 39.37 & -4.36 \\
\hline 28 & 881 & 1,208 & 1,162 & 327 & -46 & 37.12 & -3.81 \\
\hline 29 & 952 & 1,337 & 1,295 & 385 & -42 & 40.44 & -3.14 \\
\hline Total & 45,541 & 62,721 & 60,175 & 17,180 & $-2,546$ & $37.88^{7}$ & $-4.09^{7}$ \\
\hline
\end{tabular}

\footnotetext{
${ }^{1}$ Animals with birth year from 1990 to 1999.

${ }^{2}$ Animals with birth year from 2000 to 2009 .

${ }^{3}$ Animals with birth year from 2010 to 2018 .

${ }^{4}$ Differences between 2000-2009 and 1990-1999.

${ }^{5}$ Differences between 2010-2018 and 2000-2009.

${ }^{6}$ Percentage rate of change.

${ }^{7}$ Overall mean.
}

versity between markers and their surrounding QTL. In addition, the proportion of available genotyped females in Jersey were approximately $85 \%$ when compared with the available genotyped males. This is in contrast to the number of available genotyped females in Holsteins, which was approximately $70 \%$. The $\Delta F$ and $N_{e}$ estimated in the current study need to be interpreted with caution, as the genotyped animals are not a full repre-

Table 6. Correlation coefficients between the changes in unique haplotype counts within 10-yr periods (e.g., $c_{1990}-c_{1999}$ ) from 1990 to $2018^{1}$

\begin{tabular}{lccc}
\hline Period & $1990-1999$ & $2010-2018$ & $2000-2009$ \\
\hline $1990-1999$ & 0.84 & 0.66 & -0.26 \\
$2010-2018$ & -0.13 & 0.42 & 0.56 \\
$2000-2009$ & & \\
\hline
\end{tabular}

${ }^{1}$ Holstein data are presented below the diagonal and Jersey above the diagonal. sentation of the North American Holstein and Jersey populations.

Because the main objective of this present study was to investigate the trends in the rate of inbreeding and coancestry and $N_{e}$, it became apparent that investigating the changes in unique haplotype counts over time could help explain the total genetic variability available in the population. Similar trends were observed for Holsteins and Jerseys; thus, only Holsteins will be mentioned thereafter. Unique haplotype counts varied substantially across the genome; however, there was considerable loss of haplotypes on BTA3, 6, 7, 8, 13, $16,19,20,24$, and 25 over the 29-yr period. Specifically for BTA20, a large region showing high levels of positional genomic inbreeding was reported by Doekes et al. (2018) for Dutch Holsteins. The length of this region encompasses a haplotype identified in this study, hence indicating that this region could be subject to selection. Total unique haplotype counts identified per 
chromosome showed an increase from 1990-1999 to 2000-2009, which may be credited to the awareness of increasing inbreeding and implementation of measures to constrain the rate of inbreeding. Conversely, from 2000-2009 to 2010-2018 a decline occurred in the total number of unique haplotype counts. Overall, the introduction of the R-value in Canada, the expected future progeny inbreeding in the United States, and optimum contribution selection in Europe are likely the reasons for the $38.04 \%$ gain in haplotype counts for the period between 2000 and 2009. For the subsequent period between 2010 and 2018 that involved the application of GS, a $3.91 \%$ drop in haplotype counts was observed, suggesting that the drop could likely be associated with the implementation of GS. The correlation coefficients between the unique haplotype counts from the 3 different time periods gave a similar trend as those observed from the rate of inbreeding. The positive correlation observed between 1990-1999 and 2010-2018 suggests that in both of these periods the number of unique haplotypes is decreasing. These periods coincide with the implementation of traditional BLUP and GS, demonstrating that these methods are likely playing similar roles by increasing the rate of inbreeding. In contrast, a reduction in the rate of inbreeding and an increase in the number of unique haplotype counts was observed in the 2000-2009 time period. This may be due to the development and application of R-value, expected future progeny inbreeding, and optimum contribution selection as measures to restrict the rate of inbreeding.

\section{CONCLUSIONS}

In the present study, we observed an increase in the rate of inbreeding and coancestry and homozygosity following the implementation of GS. Based on the trends observed in the rate of inbreeding and coancestry and $N_{e}$ of Holsteins, measures that would help to prevent the negative consequences of high deleterious recessive load resulting from increasing rate of inbreeding and coancestry or random genetic drift due to small effective size should be investigated. A considerable drop in the rate of inbreeding and higher $N_{e}$ noticeable in the period before the implementation of GS may probably be attributable to the introduction of optimum contribution selection, R-value, and the expected future progeny inbreeding. Such similar measures could be adopted to constrain the rate of inbreeding at a desired level. Similarly, Jerseys should be monitored closely, as GS is causing a decrease in $N_{e}$ with an annual increase in the rate of inbreeding. Considerable heterogeneity of haplotypes across the chromosomes exist; however, there was a gradual loss of haplotypes following the introduction of GS. These losses could be associated with the observed increase in the rate of inbreeding and consequently the reduction in the $N_{e}$. The conservation of genetic resources will help to support the continuous viability of dairy populations in the long term, as well as maintaining substantial genetic diversity to remain amenable to future market and breeding scheme changes.

\section{ACKNOWLEDGMENTS}

The authors gratefully acknowledge grants provided by the DairyGen Council of Canadian Dairy Network (Guelph, Ontario, Canada), as well as financial support from the Natural Sciences and Engineering Research Council (NSERC) of Canada (Ottawa, Ontario, Canada). Christian Maltecca acknowledges funding from the Holstein Association USA (Brattleboro, VT). The authors declare that there are no conflicts of interest.

\section{REFERENCES}

Baes, C. F., B. O. Makanjuola, F. Miglior, G. Marras, J. T. Howard, A. Fleming, and C. Maltecca. 2019. Symposium review: The genomic architecture of inbreeding: How homozygosity affects health and performance. J. Dairy Sci. 102:2807-2817. https://doi.org/10 $.3168 /$ jds.2018-15520.

Bjelland, D. W., K. A. Weigel, N. Vukasinovic, and J. D. Nkrumah. 2013. Evaluation of inbreeding depression in Holstein cattle using whole-genome SNP markers and alternative measures of genomic inbreeding. J. Dairy Sci. 96:4697-4706. https://doi.org/10.3168/ jds.2012-6435.

Boichard, D. 2002. Pedig: A fortran package for pedigree analysis suited for large populations. 7th World Congr. Genet. Appl. Livest. Prod. 28-29.

Broman, K. W., and J. L. Weber. 1999. Long homozygous chromosomal segments in reference families from the centre d'Étude du polymorphisme humain. Am. J. Hum. Genet. 65:1493-1500. https: //doi.org/10.1086/302661.

Browning, S. R., and B. L. Browning. 2007. Rapid and accurate haplotype phasing and missing-data inference for whole-genome association studies by use of localized haplotype clustering. Am. J. Hum. Genet. 81:1084-1097. https://doi.org/10.1086/521987.

Chang, C. C., C. C. Chow, L. C. A. M. Tellier, S. Vattikuti, S. M. Purcell, and J. J. Lee. 2015. Second-generation PLINK: Rising to the challenge of larger and richer datasets. Gigascience 4:7. https: //doi.org/10.1186/s13742-015-0047-8.

Colleau, J. J. 2002. An indirect approach to the extensive calculation of relationship coefficients. Genet. Sel. Evol. 34:409. https://doi .org/10.1186/1297-9686-34-4-409.

Daetwyler, H. D., B. Villanueva, P. Bijma, and J. A. Woolliams. 2007. Inbreeding in genome-wide selection. J. Anim. Breed. Genet. 124:369-376. https://doi.org/10.1111/j.1439-0388.2007.00693.x.

Danecek, P., A. Auton, G. Abecasis, C. A. Albers, E. Banks, M. A. DePristo, R. E. Handsaker, G. Lunter, G. T. Marth, S. T. Sherry, G. McVean, and R. Durbin. 2011. The variant call format and VCFtools. Bioinformatics 27:2156-2158. https://doi.org/10.1093/ bioinformatics/btr330.

de Cara, M. Á. R., B. Villanueva, M. Á. Toro, and J. Fernández. 2013. Using genomic tools to maintain diversity and fitness in conservation programmes. Mol. Ecol. 22:6091-6099. https://doi.org/10 $.1111 /$ mec. 12560

Doekes, H. P., R. F. Veerkamp, P. Bijma, S. J. Hiemstra, and J. J. Windig. 2018. Trends in genome-wide and region-specific genetic diversity in the Dutch-Flemish Holstein-Friesian breeding program 
from 1986 to 2015. Genet. Sel. Evol. 50:15. https://doi.org/10 $.1186 / \mathrm{s} 12711-018-0385-\mathrm{y}$.

Falconer, D. S., and T. F. C. Mackay. 1996. Introduction to Quantitative Genetics. 4th ed. Longman, Essex, UK.

FAO. 2015. The Second Report on the State of the World's Animal Genetic Resources for Food and Agriculture. B. D. Scherf and D. Pilling, ed. FAO Commission on Genetic Resources for Food and Agriculture Assessments, Rome, Italy.

Forutan, M., S. Ansari Mahyari, C. Baes, N. Melzer, F. S. Schenkel, and M. Sargolzaei. 2018. Inbreeding and runs of homozygosity before and after genomic selection in North American Holstein cattle. BMC Genomics 19:98. https://doi.org/10.1186/s12864-018 $-4453-z$.

García-Gámez, E., G. Sahana, B. Gutiérrez-Gil, and J. J. Arranz. 2012. Linkage disequilibrium and inbreeding estimation in Spanish Churra sheep. BMC Genet. 13:43. https://doi.org/10.1186/1471 $-2156-13-43$

García-Ruiz, A., J. B. Cole, P. M. VanRaden, G. R. Wiggans, F. J. Ruiz-López, and C. P. Van Tassell. 2016. Changes in genetic selection differentials and generation intervals in US Holstein dairy cattle as a result of genomic selection. Proc. Natl. Acad. Sci. USA 113:E3995. https://doi.org/10.1073/pnas.1519061113.

Guarini, A. R., M. Sargolzaei, L. F. Brito, V. Kroezen, D. A. L. Lourenco, C. F. Baes, F. Miglior, J. B. Cole, and F. S. Schenkel. 2019. Estimating the effect of the deleterious recessive haplotypes AH1 and AH2 on reproduction performance of Ayrshire cattle. J. Dairy Sci. 102:5315-5322. https://doi.org/10.3168/jds.2018-15366.

Haldane, J. B. S. 1954. An exact test for randomness of mating. J. Genet. 52:631-635. https://doi.org/10.1007/BF02981502.

Hayes, B. J., P. M. Visscher, H. C. McPartlan, and M. E. Goddard. 2003. Novel multilocus measure of linkage disequilibrium to estimate past effective population size. Genome Res. 13:635-643. https://doi.org/10.1101/gr.387103.

Hazel, L. N., and J. L. Lush. 1942. The efficiency of three methods of selection. J. Hered. 33:393-399. https://doi.org/10.1093/ oxfordjournals.jhered.a105102.

Henderson, C. R. 1975. Best linear unbiased estimation and prediction under a selection model. Biometrics 31:423. https://doi.org/ $10.2307 / 2529430$

Hill, W. G., and A. Robertson. 1968. Linkage disequilibrium in finite populations. Theor. Appl. Genet. 38:226-231. https://doi.org/10 .1007/BF01245622.

Hillestad, B., J. A. Woolliams, T. H. E. Meuwissen, D. I. Våge, and G. Klemetsdal. 2014. Estimating rate of inbreeding and effective population size using genomic data in Norwegian red cattle. Page 470 in 10th World Congress of Genetics Applied to Livestock Production. Vancouver, British Columbia, Canada.

Howard, J. T., J. E. Pryce, C. Baes, and C. Maltecca. 2017. Invited review: Inbreeding in the genomics era: Inbreeding, inbreeding depression, and management of genomic variability. J. Dairy Sci. 100:6009-6024. https://doi.org/10.3168/jds.2017-12787.

Keller, M. C., P. M. Visscher, and M. E. Goddard. 2011. Quantification of inbreeding due to distant ancestors and its detection using dense single nucleotide polymorphism data. Genetics 189:237-249. https://doi.org/10.1534/genetics.111.130922.

Leroy, G., T. Mary-Huard, E. Verrier, S. Danvy, E. Charvolin, and C. Danchin-Burge. 2013. Methods to estimate effective population size using pedigree data: Examples in dog, sheep, cattle and horse. Genet. Sel. Evol. 45:1. https://doi.org/10.1186/1297-9686-45-1.

Leutenegger, A.-L., B. Prum, E. Génin, C. Verny, A. Lemainque, F. Clerget-Darpoux, and E. A. Thompson. 2003. Estimation of the inbreeding coefficient through use of genomic data. Am. J. Hum. Genet. 73:516-523. https://doi.org/10.1086/378207.

MacCluer, J. W., A. J. Boyce, B. Dyke, L. R. Weitkamp, D. W. Pfenning, and C. J. Parsons. 1983. Inbreeding and pedigree structure in standardbred horses. J. Hered. 74:394-399. https://doi.org/10 .1093/oxfordjournals.jhered.a109824.

McQuillan, R., A.-L. Leutenegger, R. Abdel-Rahman, C. S. Franklin, M. Pericic, L. Barac-Lauc, N. Smolej-Narancic, B. Janicijevic, O. Polasek, A. Tenesa, A. K. MacLeod, S. M. Farrington, P. Rudan,
C. Hayward, V. Vitart, I. Rudan, S. H. Wild, M. G. Dunlop, A. F. Wright, H. Campbell, and J. F. Wilson. 2008. Runs of homozygosity in European populations. Am. J. Hum. Genet. 83:359-372. https://doi.org/10.1016/j.ajhg.2008.08.007.

Meuwissen, T. H. E. 1997. Maximizing the response of selection with a predefined rate of inbreeding: Overlapping generations. J. Anim. Sci. 75:934-940. https://doi.org/10.2527/1997.754934x.

Meuwissen, T. H. E., B. J. Hayes, and M. E. Goddard. 2001. Prediction of total genetic value using genome-wide dense marker maps. Genetics 157:1819-1829

Mucha, S., R. Mrode, I. MacLaren-Lee, M. Coffey, and J. Conington. 2015. Estimation of genomic breeding values for milk yield in UK dairy goats. J. Dairy Sci. 98:8201-8208. https://doi.org/10.3168/ jds.2015-9682.

Pryce, J. E., M. Haile-Mariam, M. E. Goddard, and B. J. Hayes. 2014. Identification of genomic regions associated with inbreeding depression in Holstein and Jersey dairy cattle. Genet. Sel. Evol. 46:71. https://doi.org/10.1186/s12711-014-0071-7.

Purfield, D. C., D. P. Berry, S. McParland, and D. G. Bradley. 2012. Runs of homozygosity and population history in cattle. BMC Genet. 13:70. https://doi.org/10.1186/1471-2156-13-70.

Rodríguez-Ramilo, S. T., J. Fernández, M. A. Toro, D. Hernández, and B. Villanueva. 2015. Genome-Wide estimates of coancestry, inbreeding and effective population size in the Spanish Holstein population. PLoS One 10:e0124157. https://doi.org/10.1371/ journal.pone.0124157.

Sargolzaei, M. 2014. SNP1101 User's Guide. Version 1. HiggsGene Solutions Inc., Guelph, Ontario, Canada.

Sargolzaei, M., J. P. Chesnais, and F. S. Schenkel. 2014. A new approach for efficient genotype imputation using information from relatives. BMC Genomics 15:478. https://doi.org/10.1186/1471 $-2164-15-478$

Sargolzaei, M., H. Iwaisaki, and J. J. Colleau. 2005. A fast algorithm for computing inbreeding coefficients in large populations. J. Anim. Breed. Genet. 122:325-331. https://doi.org/10.1111/j.1439 -0388.2005.00538.x.

Sargolzaei, M., F. S. Schenkel, G. B. Jansen, and L. R. Schaeffer. 2008. Extent of linkage disequilibrium in Holstein cattle in North America. J. Dairy Sci. 91:2106-2117. https://doi.org/10.3168/jds 2007-0553.

Schaeffer, L. R. 2006. Strategy for applying genome-wide selection in dairy cattle. J. Anim. Breed. Genet. 123:218-223. https://doi.org/ 10.1111/j.1439-0388.2006.00595.x.

Simm, G. 2000. Genetic Improvement of Cattle and Sheep. Farming Press, Tonbridge, UK.

Smith, J. M., and J. Haigh. 1974. The hitch-hiking effect of a favourable gene. Genet. Res. 23:23-35. https://doi.org/10.1017/ S0016672300014634.

Sonesson, A. K., J. A. Woolliams, and T. H. E. Meuwissen. 2012. Genomic selection requires genomic control of inbreeding. Genet. Sel. Evol. 44:27. https://doi.org/10.1186/1297-9686-44-27.

Sørensen, A. C., M. K. Sørensen, and P. Berg. 2005. Inbreeding in Danish dairy cattle breeds. J. Dairy Sci. 88:1865-1872. https://doi .org/10.3168/jds.S0022-0302(05)72861-7.

Stachowicz, K., M. Sargolzaei, F. Miglior, and F. S. Schenkel. 2011. Rates of inbreeding and genetic diversity in Canadian Holstein and Jersey cattle. J. Dairy Sci. 94:5160-5175. https://doi.org/10.3168/ jds.2010-3308

Sved, J. A. 1971. Linkage disequilibrium and homozygosity of chromosome segments in finite populations. Theor. Popul. Biol. 2:125141. https://doi.org/10.1016/0040-5809(71)90011-6.

Uimari, P., and M. Tapio. 2011. Extent of linkage disequilibrium and effective population size in Finnish Landrace and Finnish Yorkshire pig breeds. J. Anim. Sci. 89:609-614. https://doi.org/10 $.2527 /$ jas.2010-3249.

Van Doormaal, B. J., G. Kistemaker, and P. Brand. 2003. Development of R-values to represent an animal's genetic relationship to the active female population. Guelph, Ontario, Canada. Accessed Jul. 5, 2018. http://animalbiosciences.uoguelph.ca/ fleminga/ dcbgc/Agenda0309/0903Minutes.pdf. 
VanRaden, P. M. 2008. Efficient methods to compute genomic predictions. J. Dairy Sci. 91:4414-4423. https://doi.org/10.3168/jds .2007-0980

VanRaden, P. M., K. M. Olson, D. J. Null, and J. L. Hutchison. 2011a. Harmful recessive effects on fertility detected by absence of homozygous haplotypes. J. Dairy Sci. 94:6153-6161. https://doi.org/10 $.3168 /$ jds.2011-4624.

VanRaden, P. M., K. M. Olson, G. R. Wiggans, J. B. Cole, and M. E. Tooker. 2011b. Genomic inbreeding and relationships among Holsteins, Jerseys, and Brown Swiss. J. Dairy Sci. 94:5673-5682. https://doi.org/10.3168/jds.2011-4500.

VanRaden, P. M., and L. A. Smith. 1999. Selection and mating considering expected inbreeding of future progeny. J. Dairy Sci. 82:27712778. https://doi.org/10.3168/jds.S0022-0302(99)75534-7.

Welsh, C. S., T. S. Stewart, C. Schwab, and H. D. Blackburn. 2010. Pedigree analysis of 5 swine breeds in the United States and the implications for genetic conservation. J. Anim. Sci. 88:1610-1618. https://doi.org/10.2527/jas.2009-2537.

Wiggans, G. R., T. S. Sonstegard, P. M. VanRaden, L. K. Matukumalli, R. D. Schnabel, J. F. Taylor, F. S. Schenkel, and C. P. Van Tassell. 2009. Selection of single-nucleotide polymorphisms and quality of genotypes used in genomic evaluation of dairy cattle in the United States and Canada. J. Dairy Sci. 92:3431-3436. https: //doi.org/10.3168/jds.2008-1758.

Woolliams, J. A., P. Berg, B. S. Dagnachew, and T. H. E. Meuwissen. 2015. Genetic contributions and their optimization. J. Anim. Breed. Genet. 132:89-99. https://doi.org/10.1111/jbg.12148.
Wright, S. 1922. Coefficients of inbreeding and relationship. Am. Nat. 56:330-338. https://doi.org/10.1086/279872.

Wright, S. 1931. Evolution in mendelian population. Genetics 16:97159.

Yang, J., S. H. Lee, M. E. Goddard, and P. M. Visscher. 2011. GCTA: A tool for genome-wide complex trait analysis. Am. J. Hum. Genet. 88:76-82. https://doi.org/10.1016/j.ajhg.2010.11.011.

Zhang, Q., M. P. L. Calus, B. Guldbrandtsen, M. S. Lund, and G. Sahana. 2015. Estimation of inbreeding using pedigree, 50k SNP chip genotypes and full sequence data in three cattle breeds. BMC Genet. 16:88. https://doi.org/10.1186/s12863-015-0227-7.

\section{ORCIDS}

Bayode O. Makanjuola @ https://orcid.org/0000-0002-3485-0201

Filippo Miglior @ (ttps://orcid.org/0000-0003-2345-8842

Emhimad A. Abdalla @ https://orcid.org/0000-0002-1607-3437

Christian Maltecca @ https://orcid.org/0000-0002-9996-4680

Flavio S. Schenkel $\odot$ https://orcid.org/0000-0001-8700-0633

Christine F. Baes @ https://orcid.org/0000-0001-6614-8890 